Article

\title{
Antimalarial Drugs in Ghana: A Case Study on Personal Preferences
}

\author{
Prince Yeboah $\left.{ }^{1}{ }^{(}\right)$, Arnold Donkor Forkuo ${ }^{2}(\mathbb{D}$, Obed Kwabena Offe Amponsah 1,3(D), \\ Nana Ofori Adomako ${ }^{3}{ }^{\mathbb{D}}$, Ahmad Yaman Abdin ${ }^{1}$, Muhammad Jawad Nasim ${ }^{1}{ }^{1}$, \\ Pitsch Werner ${ }^{4}\left(\mathbb{D}\right.$, Anto Berko Panyin ${ }^{3, *}$, Eike Emrich ${ }^{5}$ and Claus Jacob ${ }^{1, * \mathbb{D}}$ \\ 1 Division of Bioorganic Chemistry, School of Pharmacy, Saarland University, \\ D-66123 Saarbruecken, Germany; s8pryebo@stud.uni-saarland.de (P.Y.); \\ s8obampo@stud.uni-saarland.de (O.K.O.A.); s8ahabdi@stud.uni-saarland.de (A.Y.A.); \\ jawad.nasim@uni-saarland.de (M.J.N.) \\ 2 Department of Pharmacology, Faculty of Pharmacy and Pharmaceutical Sciences, Kwame Nkrumah \\ University of Science and Technology, PMB, Kumasi, Ghana; afdonkor.chs@knust.edu.gh \\ 3 Department of Pharmacy Practice, Faculty of Pharmacy and Pharmaceutical Sciences, Kwame Nkrumah \\ University of Science and Technology, PMB, Kumasi, Ghana; kdadomako@gmail.com \\ 4 Department for Economics and Sociology of Sports, Faculty of Economics and Empirical Human Sciences, \\ Institute of Sport Sciences, Saarland University, D-66123 Saarbruecken, Germany; \\ we.pitsch@mx.uni-saarland.de \\ 5 Faculty of Economics and Empirical Human Sciences, Saarland University, \\ D-66123 Saarbruecken, Germany; e.emrich@mx.uni-saarland.de \\ * Correspondence: berkopanyin@hotmail.com (A.B.P.); c.jacob@mx.uni-saarland.de (C.J.); \\ Tel.: +233-205-410-2277 (A.B.P.); +49-681-302-3129 (C.J.)
}

Received: 8 April 2020; Accepted: 10 April 2020; Published: 3 July 2020

First Version Published: 20 April 2020 (doi: 10.3390/sci2020028)

Second Version Published: 12 June 2020 (doi: 10.3390/sci2020045)

\begin{abstract}
Malaria is a serious infection affecting millions of people in Africa. Our study investigated the personal preferences and applications of antimalarial medicines in Ghana. Based on over 1000 questionnaires distributed in Ghana from January to May 2019, we noticed that although Western medications to fight this disease are widely available, most patients in Ghana prefer treatment with locally produced herbal remedies. This preference appears to be due to a combination of traditional venues for obtaining medicines "on the street" rather than in licensed pharmacies, trust in local and "green" products, extensive advertisement of such local products, and an inherent distrust of imported and synthetic or orthodox medicines. Going local and natural is a trend also observed in other countries across the globe and adds to the acceptance or rejection of drugs regardless of their activity or toxicity. In fact, adverse side effects associated with herbal remedies, such as general weakness, swelling and sore mouth, do not seem to deter the respondents of this study in Ghana. We propose a combination of (a) increasing public awareness of the benefits of modern medicine and (b) an improvement and control of the quality of herbal remedies to raise the standard for the treatment of malaria in countries such as Ghana.
\end{abstract}

Keywords: adverse drug reactions; antimalarial; Ghana; herbal remedies; malaria; questionnaire; street sale; orthodox medicines; patient preference

\section{Introduction}

Malaria is a serious human infection affecting around 228 million people worldwide each year, primarily in African countries such as Ghana. Caused by the Plasmodium parasite and transmitted by female Anopheles mosquitoes, this disease kills over 400,000 persons each year and impacts heavily on 
the health of millions, and also on the healthcare systems and economies of the countries affected [1,2]. Malaria can be treated with artemisinin-based combination therapies and, indeed, the World Health Organization (WHO) advocates the manufacture, import, stockpiling, distribution, and subsequent application of medicines such as artemether-lumefantrine and dihydroartemisinin-piperaquine in fixed-dose combinations in countries where malaria is endemic [3-5].

At the same time, countries such as Ghana, over the centuries, have developed a tradition in treating malaria with locally produced herbal remedies, including branded names such as Taabea or Time Herbal Mixture (Figure 1a).

(a)

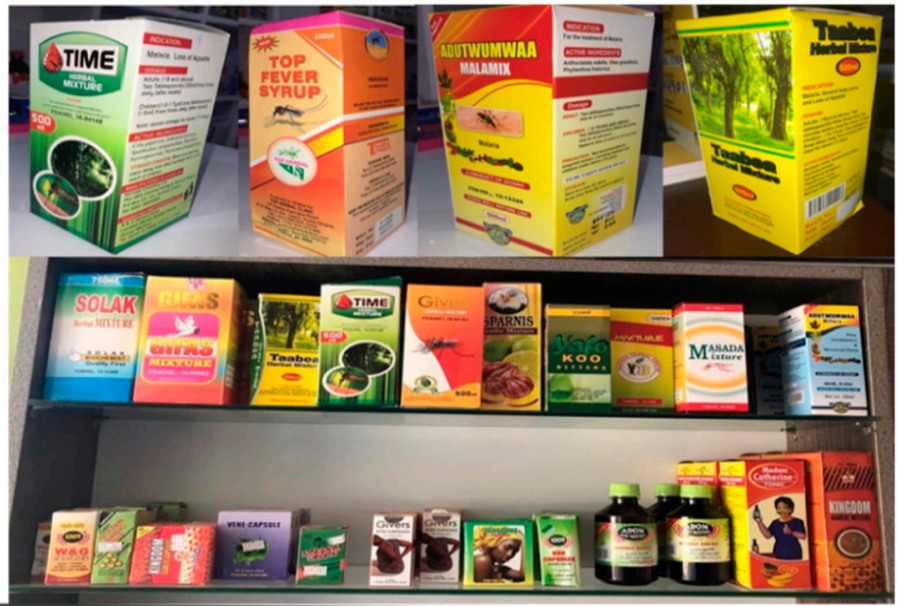

(b)
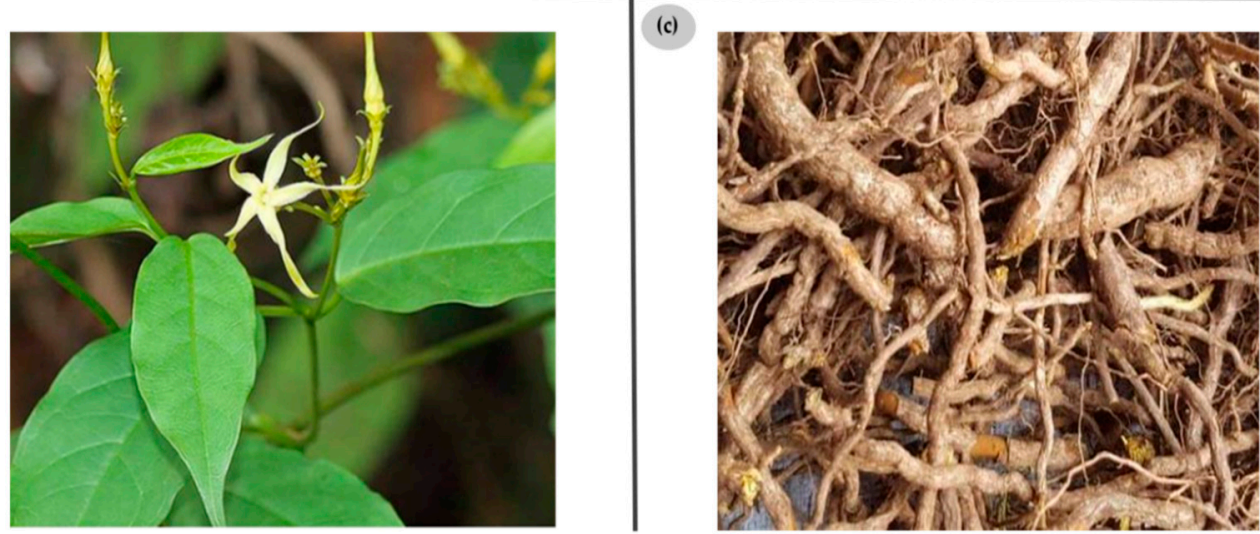

Figure 1. (a) A typical selection of locally produced herbal medications in Ghana, as found in a retail pharmacy in Kumasi - Juliponia Pharmacy Ltd, Kumasi., Ghana (source: fieldwork); (b) The aerial parts of Cryptolepis sanguinolenta [6]; (c) The roots of Cryptolepis sanguinolenta [6].

Furthermore, there is a wealth of locally produced herbal medicinal remedies, such as the one obtained from the fresh roots of Cryptolepis sanguinolenta (Figure 1c). The liquid dosage form prepared from this plant may serve as one prominent example of a herbal remedy consumed widely by the local population. For its preparation, fresh roots of $C$. sanguinolenta are harvested, washed, cut into smaller sizes and dried under shade. A specific amount of the dried roots based on the practitioner's discretion is introduced into an earthen pot followed by the addition of clean water. The fresh roots are then boiled for about $30 \mathrm{~min}$ to extract the active ingredients. The preparation is allowed to cool and filtered through a clean white cloth. The filtrate is taken by calabash or cups of different sizes three times daily as directed by the practitioners [6,7]. From a scientific perspective, C. sanguinolenta is indeed a source of natural products, such as cryptolepine and its hydrochloride, 11-hydroxycryptolepine, neocryptolepine and other alkaloids exhibiting potent antimicrobial activity against Plasmodium falciparum. In fact, 
the crude aqueous extract of this plant exhibits remarkable antimicrobial activity, especially against the chloroquine-resistant strain of P. falciparum [6,8-10].

The Ghana Health Service (GHS) guidelines permit an antimalarial to be dispensed after a positive Rapid Diagnostic Test and also state that an uncomplicated case of malaria may be treated outside a hospital setting in registered places, such as pharmacies, licensed chemical shops or herbal shops. This strategy removes some of the burden at the medical system in the country and allows a wider and uncomplicated availability of antimalarial drugs. Today, quite a few of these herbal potions are therefore sold widely and also freely over the TV, radio, and "on the street", often varying in composition and of questionable activity. Nonetheless, such medications are considered by many as an acceptable treatment of malaria and, in all fairness, also need to be distinguished clearly from more "magical" forms of treatments, such as the ones offered by fetish priests [11]. In other words, whilst such herbal remedies may not be able to rely on a firm scientific basis and scrutiny, they can rely on centuries of experience and "history" [12-15].

Based on these considerations, and with the assistance of widely distributed questionnaires, we have investigated the possible preference of the local population in Ghana for locally produced herbal versus orthodox or "Western" medications. We have tried to determine why patients prefer herbal medicines, if side effects deter the choice for such remedies, where patients obtain their antimalarial medicines, and if there are any specific deterrents or causes which may count for or against herbal remedies on one side and modern orthodox medications on the other.

\section{Materials and Methods}

In order to address these questions, a questionnaire which can be found in Supplementary Material 1 was devised. The Ethics Committee on Human Research Publication and Ethics, School of Medical Sciences and Komfo Anokye Teaching Hospital, Kwame Nkrumah University of Science and Technology (KNUST) Kumasi, Ghana approved this study and the questionnaire as not requiring ethical clearance. A total of 1200 questionnaires were distributed by qualified personnel trained by experienced lecturers in such survey studies, i.e., five postgraduate and three final year pharmacy students from the department of Pharmacy Practice, Pharmacology and Pharmaceutical Chemistry at KNUST, in some towns and regions of Ghana, as shown in Figure 2.

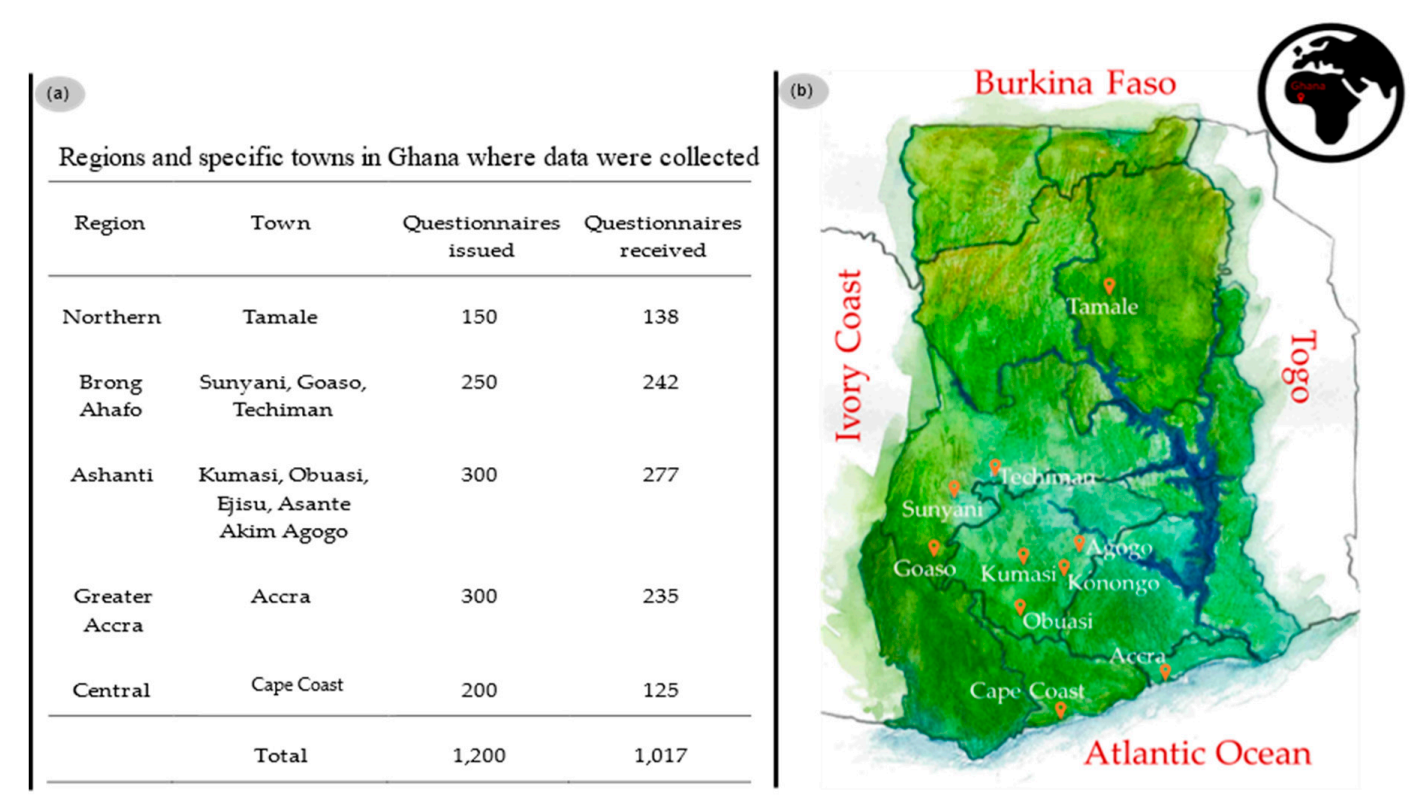

Figure 2. (a) Areas where data was collected and the number of questionnaires issued; (b) geographical location of areas data was obtained (marked with orange location pointers) (sketch provided by Leja Nessis). 
Questionnaires were handed out to the population in various locations, including marketplaces, the streets, houses, schools, retail shops and pharmacies, hospitals, offices and workplaces, etc. Respondents were selected randomly among persons who had undergone treatment for malaria in the past six to twelve months. All persons residing in Ghana for at least twelve months were selected for inclusion in the study. The questionnaire was read, explained, and translated into the local language to the participants as needed, especially for illiterates. Some respondents were guided through in filling the questionnaires which were collected after completion of the interviews. In order to prevent bias, the interviewers followed a standardized pattern in translating and explaining the content of the questionnaires "as is" to respondents. Questionnaires were filled anonymously. Respondents aged 15 to 18 were only included in the study if consent could be sought from a parent or guardian.

A total of 1017 questionnaires were obtained, of which 19 records (1.9\%) were filled inconsistently-these were edited and corrected-and there were a few records with changing and unsystematic illogical answer patterns, and these were treated as missing data on item level. Hence, all data collected could be processed further. Analyses of the data was conducted at the Faculty of Economics and Empirical Human Sciences at Saarland University employing multinomial logistic model (MLM) and multinomial logistics regression (MLRM) using R packages [16-19]. The answers provided in these questionnaires were processed at the Department of Pharmacy Practice at KNUST employing the statistics software IBM-Statistical Package and Service Solutions (IBM-SPSS) version 25 tool for data [19].

The sociodemographic of respondents comprised of 505 (50\%) males, 490 (48\%) females, whilst $19(2 \%)$ preferred not to state. The age ranged between the youth 15-19 years, 87 (9\%), 20-24 years, 257 (25\%); early adulthood 25-29 years, 202 (20\%); adulthood 30-39 years, 218 (21\%); and late adulthood $\geq 40$ years 253 (25\%). The educational levels were reported as Basic education, 449 (44\%); Secondary education, 369 (36\%); Tertiary education, 137 (14\%); and no formal education, 60 (6\%). Respondents cut across different sectors of the economy: Farmers, 375 (37\%); Traders, 200 (20\%); Professional workers, 135 (13\%); Businessmen/women, 112 (11\%); Drivers, 97 (10\%); and Students, 89 (9\%).

\section{Results}

One of the initial hypotheses of our study stated that the limited availability and/or high costs of modern synthetic antimalarial medicines prevent the local population from taking such medicines and encourage them to rely on less efficient and often dubious herbal remedies obtained from non-conventional distributors [20-23]. The results obtained as part of this study paint a different, more differentiated picture. Around two-thirds of respondents rely exclusively, or in part, on herbal medications which are purchased in response to advertising or from drug peddlers, and in less than one-fifth of the cases, from pharmacies. The preference of herbal over synthetic medications correlate with education and age, respectively. In fact, the higher the education, the higher the chances of choosing "herbal". These and other often-unexpected findings will now be presented and discussed in more detail.

\subsection{Herbal or Orthodox}

Among the 1017 respondents questioned about their choice of antimalarial drugs, only 31\% prefer orthodox, i.e., synthetic medicines produced by local pharmaceutical companies or imported into Ghana, as shown in Figure 3a. In contrast, 36.8\% of respondents rely on locally produced herbal remedies and $32.2 \%$ on a combination of both. 

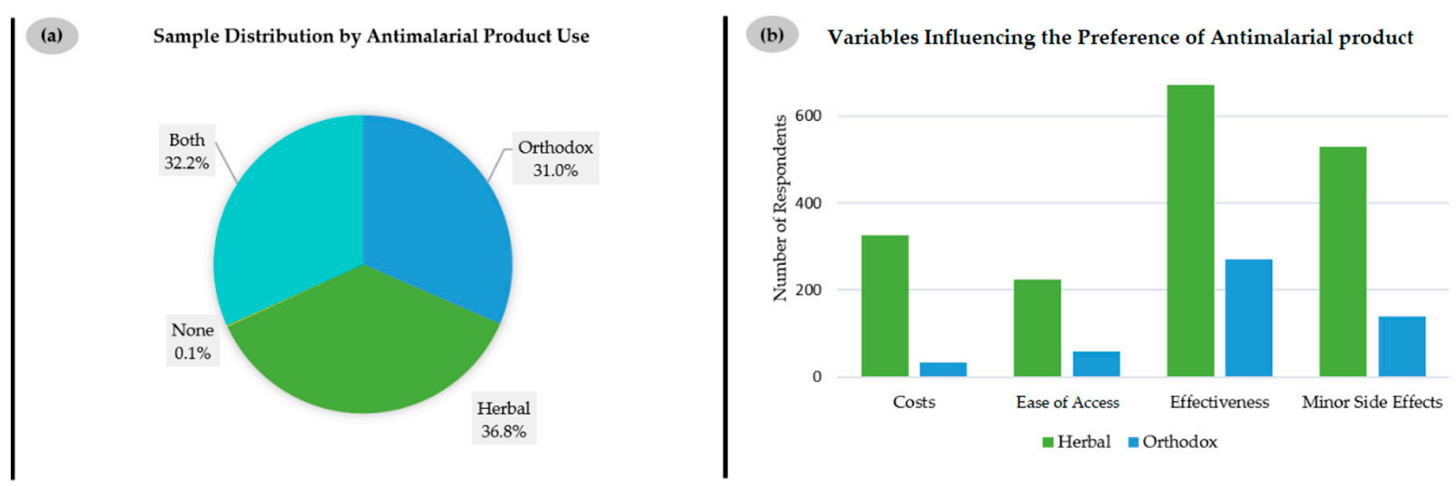

Figure 3. (a) Type of antimalarial agent utilized; (b) Reasons for choosing the type of antimalarial agent.

It is interesting to note that the choice for herbal remedies is not simply one of ease of access or costs. In fact, most respondents, i.e., over half of all 1008 persons who responded, consider "effectiveness" as the most important aspect for choosing herbal $(n=672)$ and also orthodox medications $(n=286)$, closely followed by "minor side effects", as indicated in Figure 3b. Whilst the issue of "costs" is still important to 325 respondents choosing herbal medications and just 48 respondents preferring orthodox products, it is not the main reason for "going herbal". The same applies to "ease of access", which only matters to 225 customers of herbal and 60 customers of orthodox medications. These findings reject the common conception that limited access to Western antimalarial medication may be a reason for switching to herbal products and point towards other reasons for this apparent preference [24].

As Table 1 indicates, this general preference for herbal medicines increases with education and is independent of gender. There is a statistically highly significant correlation between the type of antimalarial medicine chosen and education. The choice for herbal in comparison to orthodox $(p<0.02)$ or both orthodox and herbal to orthodox $(p<0.01)$ is statistically significant.

Table 1. Variables influencing the utilization/choice of herbal antimalarials against orthodox antimalarial and combination of herbal antimalarial medicine with orthodox antimalarial medicine.

\begin{tabular}{|c|c|c|c|c|c|c|c|c|c|c|}
\hline \multirow{3}{*}{ Variable } & \multicolumn{5}{|c|}{ Herbal vs. Orthodox } & \multicolumn{5}{|c|}{ Herbal vs. Herbal + Orthodox } \\
\hline & \multicolumn{5}{|c|}{$\begin{array}{l}\text { 95\% Confidence Interval } \\
\text { for Odds Ratio }\end{array}$} & \multicolumn{5}{|c|}{$\begin{array}{l}\text { 95\% Confidence Interval } \\
\text { for Odds Ratio }\end{array}$} \\
\hline & $\begin{array}{c}B \\
* \text { (SE) }\end{array}$ & Lower & $\begin{array}{l}\text { Odds } \\
\text { Ratio }\end{array}$ & Upper & $\begin{array}{c}p \\
\text {-Value }\end{array}$ & $\begin{array}{c}B \\
*(\mathrm{SE})\end{array}$ & Lower & $\begin{array}{l}\text { Odds } \\
\text { Ratio }\end{array}$ & Upper & $\begin{array}{c}p \\
\text {-Value }\end{array}$ \\
\hline Age & $\begin{array}{l}-0.10 \\
(0.06)\end{array}$ & 0.80 & 0.90 & 1.01 & 0.08 & $\begin{array}{c}0.01 \\
(0.06)\end{array}$ & 0.90 & 1.01 & 1.13 & 0.93 \\
\hline Education & $\begin{array}{c}0.22 \\
(0.09)\end{array}$ & 1.04 & 1.24 & 1.48 & $<0.02$ & $\begin{array}{c}0.28 \\
(0.09)\end{array}$ & 1.12 & 1.33 & 1.57 & $<0.01$ \\
\hline Gender & $\begin{array}{c}0.15 \\
(0.13)\end{array}$ & 0.91 & 1.17 & 1.50 & 0.23 & $\begin{array}{l}-0.02 \\
(0.13)\end{array}$ & 0.76 & 0.98 & 1.26 & 0.88 \\
\hline
\end{tabular}

Assay: (MLM); B-Beta Value; * SE (standard error); 95\% CI; $p<0.05$.

The impact of the advice of a caregiver, i.e., medical practitioner or pharmacist, on the choice of the type of antimalarial drug was also studied. The analysis to adhere to a preferred type of antimalarial, herbal or orthodox-when one is given a different type- reveals that age contributes significantly to the preference for herbal over orthodox medicines $(p<0.01)$ as increasing age corresponds to an increase in the preference for herbal antimalarial remedies as illustrated in Table 2. 
Table 2. Impelling variables to adhere to the preferred type of antimalarial despite being given a different type of antimalarial drug.

\begin{tabular}{|c|c|c|c|c|c|}
\hline \multirow{2}{*}{ Variable } & \multicolumn{5}{|c|}{ 95\% Confidence Interval for Odds Ratio } \\
\hline & $B *(\mathrm{SE})$ & Lower & Odds Ratio & Upper & $p$-Value \\
\hline Age & $-0.14(0.05)$ & 0.79 & 0.87 & 0.96 & $<0.01^{* *}$ \\
\hline Education & $0.15(0.08)$ & 0.98 & 1.16 & 1.37 & 0.08 \\
\hline Gender & $-0.10(0.11)$ & 0.72 & 0.90 & 1.12 & 0.37 \\
\hline
\end{tabular}

Assay: (MLM); B-Beta Value; ${ }^{*}$ SE (standard error); 95\% CI; $p<0.05$; VIF (variance inflation factor) $>10$ (no multicollinearity); ${ }^{* *}(p<0.01)$.

\subsection{The Role of Drug Advertisements and Peddlers}

The claim by many respondents that such herbal medications are particularly effective, which is implicit in Figure 3b, is rarely supported by scientific evidence. Indeed, there are only a few studies on the composition and activity of such herbal medicines against malaria, such as the one on C. sanguinolenta mentioned already $[1,2]$. Nonetheless, there is a major local industry behind such herbal medications, which relies on "tradition" to support its distribution. Indeed, when asked about the sources of such herbal medicines, less than one-fifth of respondents mentioned a prescription or pharmacy $(18.4 \%)$, while a smaller fraction cited a licensed chemical shop (14.1\%), i.e., a small-scale retail drug store operated by a non-pharmacist licensed to sell over-the-counter medications in Ghana. A vast majority of the respondents obtained such remedies from advertised agents (30.7\%), i.e., local herbal producers and sellers who mostly publicize their herbal medications on all kinds of media platforms, including print media, broadcast news and the internet, and drug peddlers $(23.2 \%)$, i.e., a group of vendors who sell medications without license in public places such as in the streets, in public transport and at people's residences or workplaces. By contrast, traditional healers, i.e., practitioners, licensed or unlicensed, who produce medications from animal and/or plant sources to cure diseases—which one may associate spontaneously with such herbal remedies—only represent a very minor source of such products $(7.3 \%)$ (Figure $4 a)$.
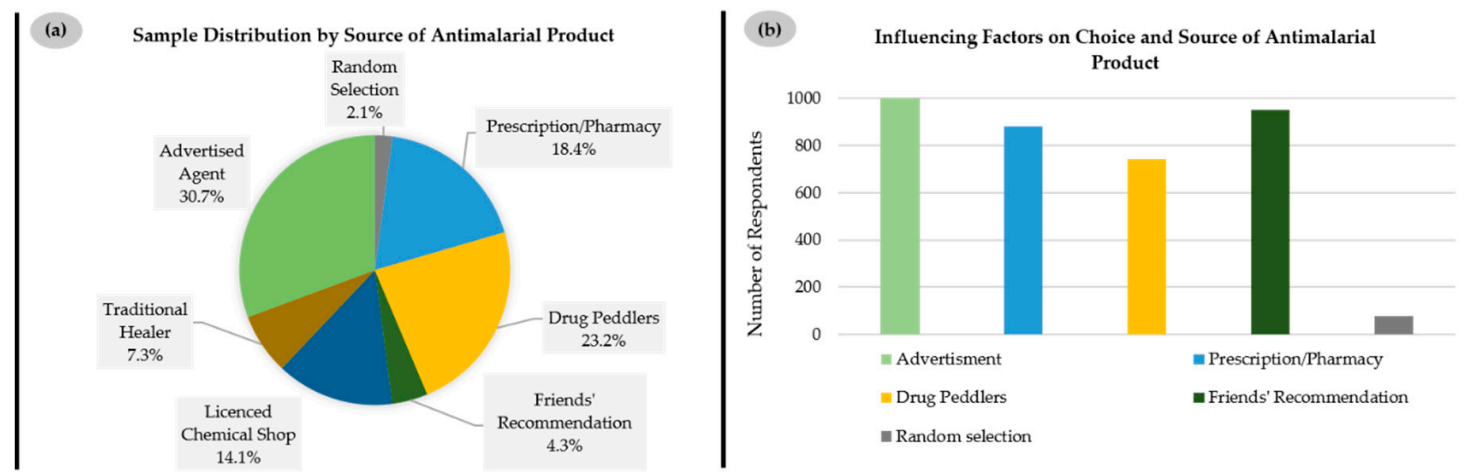

Figure 4. (a) Access points/sources of herbal antimalarials; (b) Factors influencing choice and source of herbal antimalarials in Ghana.

The influence of such advertisements is also reflected in the answers to the question regarding factors influencing the choice of source of antimalarial medications, where virtually all respondents felt affected by "advertisement" on places such as local TV stations, radio stations, and advertising signboards in streets (1016 out of 1017, 99.9\%), with "friends' recommendation" second (950 out of 1015, 93.6\%), before "prescription/pharmacy" (881 out of 1004, 87.7\%) and "drug peddlers" (743 out of 1017, 73.1\%) (Figure 4 b).

Together, these numbers point towards a very differentiated and perhaps unexpected image of the choice and acquisition of antimalarial drugs in countries such as Ghana. Rather than simply visiting a 
doctor or pharmacist, obtaining counseling and a prescription, and then purchasing a prescription antimalarial drug in the pharmacy, locally produced herbal medications are being advertised and sold openly "on the street" to customers of all ages, gender, educational backgrounds, and occupations.

\subsection{Adverse Side Effects and Drug Reactions (ADRs)}

Such findings are rather alarming as such herbal remedies may result in serious adverse side effects (adverse drug reactions, ADRs), such as blocked/ringing ears, blurred vision, itching, nausea and vomiting, general body weakness, and significant disability. Indeed, most of the consumers (687 out of 1008, 68.2\%) of such herbal preparations have reported such ADRs, which either resolved by themselves (416 out of $678,61.4 \%$ ) or, in extreme cases, required hospitalization (118 out of 678, $17.4 \%$ ) (Figure 5).

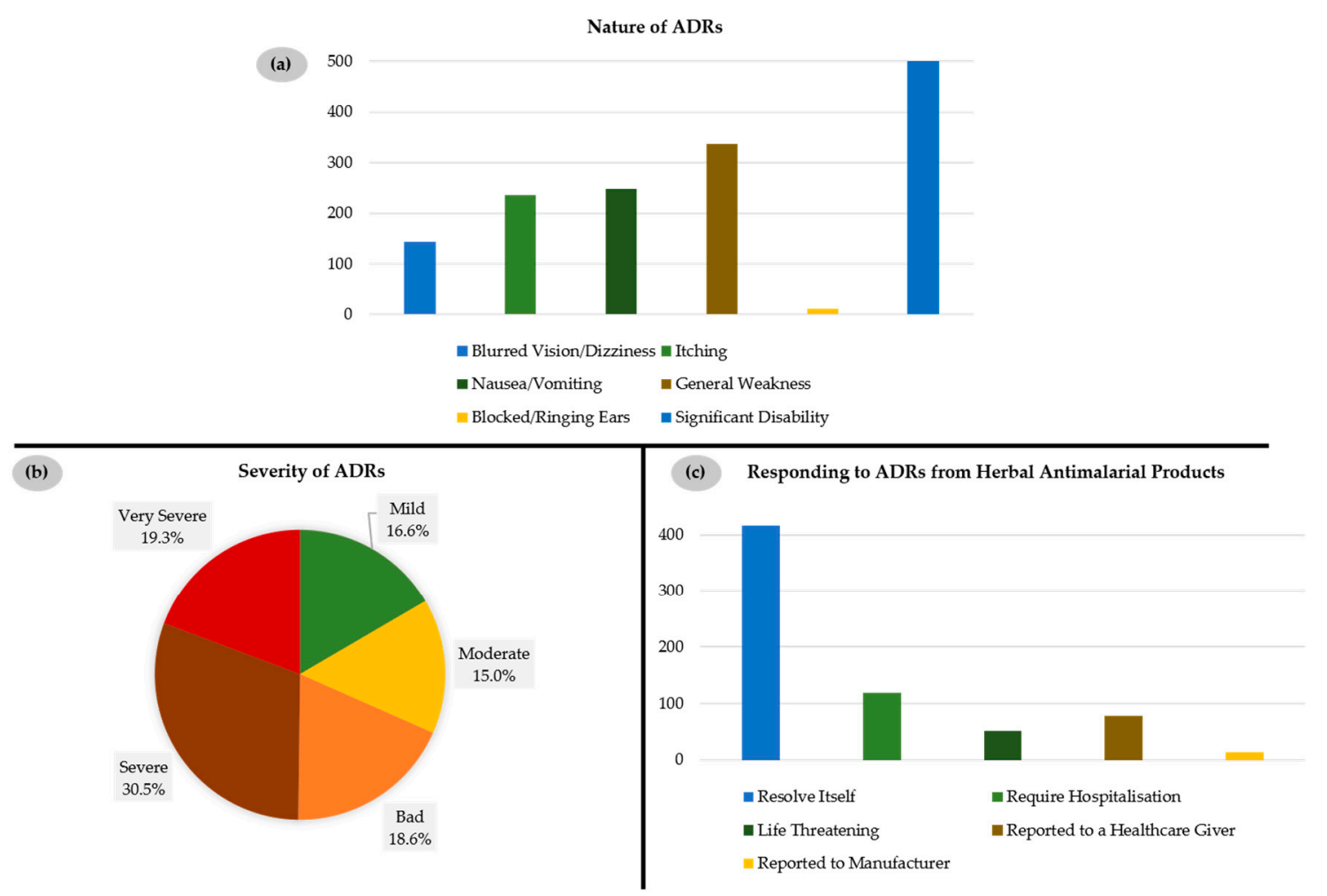

Figure 5. (a) Nature of adverse drug reactions (ADRs) experienced by respondents; (b) Severity of ADRs experienced by respondents; (c) Individual responses to ADRs from herbal antimalarial medicines.

The ADRs observed by respondents could indeed be linked to herbal remedies as in $94 \%$ of reported cases they occurred only during treatment. Furthermore, in $86 \%$ of reported cases, these ADRs resolved themselves after discontinuing the treatment. Interestingly, only $42 \%$ of respondents affected by such ADRs refrained from further administration, whilst $58 \%$ continued treatment despite experiencing these ADRs and despite the option to obtain an orthodox drug.

It is also quite interesting to note that the source of such herbal medication correlates strongly with ADRs, with remedies from traditional healers $(p<0.01)$ or those purchased from drug peddlers $(p<0.02)$ particularly prone to cause ADRs. In stark contrast, with medication recommended by friends, i.e., offered or directed to buy by a friend $(p<0.04)$ per the odds ratio, the probability of ADRs decreases (Table 3). 
Table 3. Relationship between sources of herbal antimalarials and ADRs with odds ratios of experiencing no ADRs in relation to the probability to experience ADRs.

\begin{tabular}{|c|c|c|c|c|c|}
\hline \multirow{2}{*}{ Source } & \multicolumn{5}{|c|}{ 95\% Confidence Interval for Odds Ratio } \\
\hline & $B *(\mathrm{SE})$ & Lower & Odds Ratio & Upper & $p$-Value \\
\hline Advertised places & \multicolumn{5}{|c|}{ Reference category } \\
\hline Prescription/pharmacy & $-0.09(0.19)$ & 0.62 & 0.91 & 1.33 & 0.63 \\
\hline Drug peddlers & $-0.45(0.19)$ & 0.44 & 0.64 & 0.92 & 0.02 \\
\hline Friends' recommendation & $0.65(0.32)$ & 1.02 & 1.92 & 3.62 & 0.04 \\
\hline Licensed chemical shop & $-0.08(0.22)$ & 0.61 & 0.93 & 1.41 & 0.72 \\
\hline Traditional healer & $-1.17(0.35)$ & 0.16 & 0.31 & 0.61 & $<0.01$ \\
\hline
\end{tabular}

Assay: (MLRM); B-Beta Value; * SE (standard error); $95 \%$ CI; $p<0.05$.

Herbal remedies from pharmacies and licensed chemical shops show no correlation with the reporting of ADRs. It is also noteworthy that respondents who have selected specific herbal medicines for the reasons of "cost" per the odds ratio have a rather higher chance of experiencing ADRs. Ironically, drugs advertised as having "minor side effects" were significantly positively correlated with an increased chance of experiencing ADRs $(p<0.01)$ (Table 4).

Table 4. Relationship between the reason for choosing a specific type of antimalarial agent and ADRs with odds ratios to experience no ADRs in relation to experience ADRs.

\begin{tabular}{cccccc}
\hline \multirow{2}{*}{ Reason } & \multicolumn{5}{c}{ 95\% Confidence Interval for Odds Ratio } \\
\cline { 2 - 6 } & $\boldsymbol{B}^{*}$ (SE) & Lower & Odds Ratio & Upper & $p$-Value \\
\hline Cost & $-1.84(0.21)$ & 0.11 & 0.16 & 0.24 & $<0.01^{* * *}$ \\
Ease of access & $-0.36(0.19)$ & 0.48 & 0.70 & 1.02 & 0.06 \\
Effectiveness & $-0.31(0.18)$ & 0.52 & 0.73 & 1.04 & 0.08 \\
Minor side effects & $-0.65(0.16)$ & 0.38 & 0.52 & 0.70 & $<0.01^{* * *}$ \\
\hline ssay: (MLRM); B-Beta Value; ${ }^{*}$ SE (standard error); 95\% CI; $p<0.05 ;$ VIF (variance inflation factor) $>10$ \\
no multicollinearity); ${ }^{* * *}(p<0.001)$.
\end{tabular}

(no multicollinearity); ${ }^{* * *}(p<0.001)$.

\section{Discussion}

The results obtained as part of this study point towards a rather unexpected and quite differentiated situation of antimalarial drugs in Ghana. A naïve observer may initially expect that antimalarial drugs in Ghana would be prescribed by qualified medical personnel and then obtained as a modern prescription drug in a pharmacy $[4,25,26]$. Whilst one may also expect that this may differ in the countryside, such a Western-style acquisition of drugs should be common in larger cities such as Accra and Kumasi.

\subsection{Herbal Medications are Preferred Because of Trust}

Based on the results obtained as part of this study, and relying on over 1000 participants from across society, this simplistic picture is flawed for a number of reasons. First of all, medications and remedies in Ghana are not distributed solely by pharmacies and licensed chemical shops. As illustrated in Figure 4a, only $32.5 \%$ of the population purchase their herbal drugs against malaria in pharmacies or licensed chemical shops. These herbal medications are available rather widely and often sold in some unlicensed shops or by mobile drug peddlers. Here, a rather unexpected picture of locally produced herbal remedies filling the "drug depository" is painted in this study, as these herbal remedies are clearly more readily available to such vendors when compared to prescription drugs, as indicated already in Figure 1a. They must also be considered as one important economic factor in Ghana, which has only a small Western-style pharmaceutical industry. Herbal medication is therefore actively promoted by this national industry. 
Nonetheless, availability is not the only reason why herbal medications are preferred in Ghana. In the region we have studied, there is no inherent shortage of orthodox medicines, and "cost" is also not the decisive factor. According to the data shown in Figure 3b, one may assume that trust plays a decisive role. Medications are often recommended by trusted friends or produced locally by trusted companies according to age-old trusted Ghanaian recipes. Advertisement, such as the one shown in Figure $4 \mathrm{~b}$, also plays on trust. This kind of trust must also be one of the reasons why respondents prefer herbal remedies because of "effectiveness", which is rather curious, as most of these agents might not have been scrutinized for activity, let alone proven to be effective against malaria [12,27].

In stark contrast to this trust in and promotion of traditional remedies, imported drugs from major drug companies which, from a scientific point of view, are considerably more trustworthy, are not being advertised in this manner, and may be considered as "foreign" [28-30]. Here, there is a specific distrust felt against drugs produced in countries by themselves not exposed to malaria. At the same time, there is a certain resentment against synthetic substances, in comparison to the "natural" herbal remedies.

\subsection{Social Aspects Influencing the Choice of Drug}

Both of these social and psychological aspects influencing the choice of cure are neither bizarre nor specific to Ghana. Although we cannot present any firm data on this, local or national products also feature highly on the agenda in countries across the globe. In Germany, for instance, local and national products are preferred, from locally produced vegetables in the supermarket or from the corner shop, to the faible for German cars. Similarly, alternative medications and, here in particular, herbal remedies, are also widely sold and administered, from valerian sedatives to concentrated brine to chase your intestinal worms-the majority "made in Germany" or produced at home, just as the brew based on C. sanguinolenta discussed in the Introduction and Figure 1b,c. Likewise, in Ghana, natural "green" products are considered as better or even superior to "chemical", although most of them may be less active or not active, and are also likely to cause adverse reactions. These products are advertised widely on TV and in magazines and can be sold more widely, without prescriptions and outside pharmacies.

Our data therefore confirms once more that such social aspects influencing the choice of a particular drug must be considered in formulating national and international policy to tackle health issues. It is therefore not sufficient to provide a country such as Ghana with the necessary amounts of modern antimalarial medication. This medication also has to be "sold", literally, as an effective and trustworthy alternative to traditional remedies. Once again, this matter of trust appears to be strong across the population and regardless of education or occupation. In fact, respondents with higher education are particularly keen on herbal remedies, possibly because of their fondness for "natural" rather than "chemical" products. The trust in herbal remedies also overrides justified scientific questions on the effectiveness and risk of ADRs. Indeed, almost half of the respondents stated that they continue to take such herbal remedies despite experiencing ADRs which, in some instances, have actually led to hospitalization.

\subsection{ADRs}

According to our study, the majority of those respondents who have indicated employing either only herbal or a combination of herbal and orthodox medicine, have experienced some ADRs during the course of treatment with herbal medicines (687 out of 1008, 68.2\%), ranging from mild (16.6\%) to severe ADRs (49.8\%). These problems have not deterred the respondents from continuing such treatments. The source of the herbal medicine, i.e., either from a pharmacy or licensed chemical shop, on one side, and from a drug peddler or traditional healer on the other, also influences the quality. It is therefore important to distinguish between the different types of herbal medicines available in Ghana, as some of them may indeed be more amenable than others. In general, the population study presented here confirms that most of these herbal remedies cause a range of ADRs, and that this situation is far 
from acceptable and should be addressed in earnest. Ironically, the remedies assumed to exhibit few ADRs have been particularly adverse, possibly because these remedies are consumed more widely thanks to their "good reputation" [27,31].

\subsection{Improving the Situation}

It is obvious that the present situation of antimalarial medication in Ghana is far from satisfactory. This is due to a complicated medley of personal preferences, reputation, trust, and advertisement by local producers and vendors. There are also several social and personal preferences for locally produced herbal remedies, an attitude not unique to Ghana. Indeed, one could probably generalize the outcomes of this study to other countries of Western Africa and beyond.

At the same time, the situation also provides certain clues for improvement. On one side, modern medicine based on extensive scientific research and validation needs to obtain a better reputation as this kind of medicine is probably more active and causes limited ADRs. Nonetheless, changing people's attitudes may not be simple. One valuable alternative, therefore, is more extensive research and development into the existing herbal remedies [13,14,32-36]. This may provide a refinement of the most active mixtures, i.e., higher efficacy and few ADRs. Indeed, such a strategy has several major advantages. Firstly, such remedies have been taken for centuries by the local population, who is familiar with their dosage and actions [37]. Secondly, such remedies, therefore, are already accepted within society. Moreover, herbal medicines can be produced locally, which benefits the local industry and they can be sold by local vendors. Such refinements are also possible in practice, as the correlation between the source of the herbal remedy and associated ADRs in Table 3 indicates. Certain sources, such as pharmacies and licensed shops, are clearly better places to obtain better medications from, regardless if orthodox or herbal.

\subsection{Limitations}

As any survey-based investigation, our study has also experienced certain methodological limitations which may have impacted on certain details of the study, although probably not on the overall outcomes. Firstly, the study did not objectively assess the malaria status of respondents through confirmed malarial tests, relying exclusively on the assessment of respondents and their individual experiences with this infection. Regarding such experiences, it has also not been possible to rule out that some respondents had become infected more than once before and therefore had tried out various medications in the past, hence choosing the best treatment based on experience with different classes and brands of medications.

In practice, a few of the respondents also showed difficulties comprehending the questionnaires, and this issue was addressed by our trained interviewers who spent time explaining the various parameters to the respondents. This helped the respondents to respond and to provide adequate information for the questionnaire. In contrast, a certain "sloppiness" associated with answering such questionnaires had been anticipated before and was reduced by interviewers guiding respondents and collecting most of the answers on the spot. In addition, some of the respondents were skeptical about answering the questions due to fear of exposing their identity. Hence, there was the need to emphasize that the questionnaires were collected anonymously, and the data obtained was to be kept under lock and key, only accessible to the investigators. This also reduced the possibility of providing dishonest answers.

\section{Conclusions}

In summary, our study on the preferences of and treatments with antimalarial medications in Ghana has shown that despite the availability of orthodox synthetic drugs, there is a significant preference for and usage of locally produced and sold herbal remedies, in part because of personal trust and in part because of aggressive advertising and sales practices by the local producers and vendors. It can be inferred that going herbal is clearly not a matter of money, education, age, or occupation. It is 
rather a trust in local and natural products and producers, and here the respondents in Ghana hardly differ from their peers in other countries. As these herbal remedies are largely undefined and not refined as far as their contents and actions are concerned, they often trigger ADRs. Besides encouraging the local population to simply switch to "Western-style" medicine, which may be considered as interfering and arrogant, and may hence be met with resistance and probably result in little tangible benefits, a closer scientific investigation of some of the local remedies may represent a suitable alternative, such as $C$. sanguinolenta. Indeed, international research and local industry may both find advantages in such a joint approach to the vast benefits of the millions of patients suffering from this infection each year in Ghana and the rest of Africa.

Supplementary Materials: The following are available online at http://www.mdpi.com/2413-4155/2/3/49/s1, Supplementary Material 1: Questionnaire entitled, "Ethical Access and pharmacovigilance study of herbal antimalarial products in Ghana".

Author Contributions: Conceptualization, P.Y.; O.K.O.A.; N.O.A.; Methodology, P.Y., A.D.F., A.Y.A.; Validation, A.D.F., A.B.P., C.J.; Formal analysis, P.W., E.E.; Investigation, P.Y.; O.K.O.A.; N.O.A.; Data curation, P.W.; and E.E.; Writing—original draft preparation, C.J.; and P.Y.; Writing—review and editing, P.Y., O.K.O.A., N.O.A., M.J.N.; A.Y.A., C.J.; Visualization, P.Y.; Supervision, C.J., A.B.P.; Project administration, P.Y. All authors have read and agreed to the published version of the manuscript.

Funding: This research received no external funding.

Acknowledgments: The authors would like to acknowledge the help and support of Angela Owusu-Bediako, Belinda Korlekuor Agbetiameh, Williams Appiah, students who helped in the data collection and Yakubu Jibira for data input and curation. They also thank the staff of the Faculty of Pharmacy and Pharmaceutical Sciences, KNUST and the Division of Bioorganic Chemistry, School of Pharmacy, Saarland University for their immense help and direction in the various stages of this study. We would also like to thank Leja Nessis along with the many other colleagues from the Academiacs International Network (www.academiacs.eu) for their support and helpful discussions.

Conflicts of Interest: The authors declare no conflicts of interest.

\section{Abbreviations}

$\begin{array}{ll}\text { ADR } & \text { Adverse Drug Reaction } \\ \text { CI } & \text { Confidence Interval } \\ \text { GHS } & \text { Ghana Health Service } \\ \text { MLM } & \text { Multinomial Logistic Model } \\ \text { MLRM } & \text { Multinomial Logistic Regression Model } \\ \text { SE } & \text { Standard Error } \\ \text { VIF } & \text { Variance Inflation Factor } \\ \text { WHO } & \text { World Health Organization }\end{array}$

\section{References}

1. Malaria Global WHO Team. World Malaria Report 2019; World Health Organization: Geneva, Switzerland, 2019.

2. WHO. World Malaria Report 2018; WHO: Geneva, Switzerland, 2018.

3. WHO. Overview of Malaria Treatment; WHO: Geneva, Switzerland, 2019.

4. World Health Organization. Guidelines for the Treatment of Malaria; WHO: Geneva, Switzerland, $2015 ;$ p. 313.

5. Sinclair, D.; Zani, B.; Donegan, S.; Olliaro, P.; Garner, P. Artemisinin-based combination therapy for treating uncomplicated malaria. Cochrane Database Syst. Rev. 2009, 3. [CrossRef] [PubMed]

6. Osafo, N.; Mensah, K.B.; Yeboah, O.K. Phytochemical and pharmacological review of Cryptolepis sanguinolenta (Lindl.) Schlechter. Adv. Pharmacol. Sci. 2017, 2017, 13. [CrossRef] [PubMed]

7. Bugyei, K.; Boye, G.; Addy, M. Clinical efficacy of a tea-bag formulation of Cryptolepis sanguinolenta root in the treatment of acute uncomplicated falciparum malaria. Ghana Med. J. 2011, 44. [CrossRef]

8. Paulo, A.; Gomes, E.T.; Steele, J.; Warhurst, D.C.; Houghton, P.J. Antiplasmodial activity of Cryptolepis sanguinolenta alkaloids from leaves and roots. Planta Med. 2000, 66, 30-34. [CrossRef] [PubMed]

9. Cimanga, K.; De Bruyne, T.; Pieters, L.; Vlietinck, A.J.; Turger, C.A. In vitro and in vivo antiplasmodial activity of cryptolepine and related alkaloids from Cryptolepis sanguinolenta. J. Nat. Prod. 1997, 688-691. [CrossRef] 
10. Barku, V.Y.A.; Opoku-Boahen, Y.; Dzotsi, E.Y. Isolation and pharmacological activities of alkaloids from Cryptolepis sanguinolenta (Lindl) schlt. Int. Res. J. Biochem. Bioinforma. Ghana 2012, 2, 58-61.

11. Druetz, T.; Andrinopoulos, K.; Boulos, L.-M.; Boulos, M.; Noland, G.S.; Desir, L.; Lemoine, F.J.; Eisele, T.P. Wherever doctors cannot reach, the sunshine can: Overcoming potential barriers to malaria elimination interventions in Haiti. Malar. J. 2018, 17, 393. [CrossRef]

12. Willcox, M.; Benoit-Vical, F.; Fowler, D.; Bourdy, G.; Burford, G.; Giani, S.; Graziose, R.; Houghton, P.; Randrianarivelojosia, M.; Rasoanaivo, P. Do ethnobotanical and laboratory data predict clinical safety and efficacy of anti-malarial plants? Malar. J. 2011, 10, S7. [CrossRef]

13. Cam, A.J.T.; Elujoba, A.A.; Odeleye, O.M.; Ogunyemi, C.M. Review traditional medicine development for medical and dental primary health care delivery system in the orthodox medicine. Afr. J. Tradit. Complement. Altern. Med. 2005, 2, 46-61.

14. World Health Organization. General Guidelines for Methodologies on Research and Evaluation of Traditional Medicine; World Health Organization: Geneva, Switzerland, 2000.

15. Wilmot, D.; Ameyaw, E.O.; Sakyi, D.A.; Boampong, J.N.; Quashie, B.N. In vivo efficacy of top five surveyed Ghanaian herbal anti-malarial products. Malar. J. 2017, 16, 1-8. [CrossRef]

16. R Core Team. R: A Language and Environment for Statistical Computing; R Foundation for Statistical Computing: Vienna, Austria, 2019.

17. Venables, W.; Ripley, B. Modern Applied Statistics Using, S; Springer: New York, NY, USA, 2002; p. 481.

18. Fox, J.; Weisberg, S. An $\{R\}$ Companion to Applied Regression; Sage: Thousand Oaks, CA, USA, 2016.

19. IBM Corp. IBM SPSS Statistics for Windows; IBM Corp: Armonk, NY, USA, 2017.

20. Beigbeder, Y.; Beigbeder, Y. Access to Essential Medicines; The World Health Organization: Geneva, Switzerland, 2018.

21. Bigdeli, M.; Jacobs, B.; Tomson, G.; Laing, R.; Ghaffar, A.; Dujardin, B.; Damme, W.V. Access to medicines from a health system perspective. Health Policy Plan. 2013, 28, 692-704. [CrossRef]

22. (MDG) Gap Task Force Report 2011. Access to affordable essential medicines. In Millennium Development Goals; United Nations: New York, NY, USA, 2017.

23. Pogge, T. Access to medicines. Public Health Ethics 2008, 1, 73-82. [CrossRef]

24. Nyamongo, I.K. Health care switching behaviour of malaria patients in a Kenyan rural community. Soc. Sci. Med. 2002, 54, 377-386. [CrossRef]

25. WHO. Guidelines for the Treatment of Malaria, 2nd ed.; WHO: Geneva, Switzerland, 2010.

26. Ministry of Health Ghana. Guideline for case management of Malaria in Ghana, 3rd ed.; WHO: Geneva, Switzerland, 2014.

27. Grollman, A.P.; Marcus, D.M. Global hazards of herbal remedies: Lessons from aristolochia efficacy of medicinal plants Global hazards of herbal remedies. EMBO Rep. 2016, 17, 619-625. [CrossRef] [PubMed]

28. Abdullahi, A.A. Trends and challenges of traditional medicine in Africa. Afr. J. Tradit. Complement. Altern. Med. 2011, 8, 115-123. [CrossRef]

29. Rennie, S. How not to explain African distrust of western medicine. Bioethics 2007. Available online: http://www.bioethics.net/2007/08/how-not-to-explain-african-distrust-of-western-med/ (accessed on 11 December 2019).

30. Washington, H.A. Medical apartheid. In the Dark History of Medical Experimentation on Black Americans from Colonial Times to the Present; Doubleday Books: New York, NY, USA, 2006; p. 501.

31. Ekor, M. The growing use of herbal medicines: Issues relating to adverse reactions and challenges in monitoring safety. Front. Pharmacol. 2014, 4, 177. [CrossRef]

32. Boadu, A.A.; Asase, A. Documentation of herbal medicines used for the treatment and management of human diseases by some communities in southern Ghana. Evid. Based Complement Alternat. Med. 2017, 2017, 12. [CrossRef]

33. Wells, T.N. Natural products as starting points for future anti-malarial therapies: Going back to our roots? Malar. J. 2011, 10. [CrossRef]

34. Willcox, M. Improved traditional phytomedicines in current use for the clinical treatment of malaria. Planta Med. 2011, 77, 662-671. [CrossRef]

35. World Health Organization. WHO Guidelines on Safety Monitoring of Herbal Medicines in Pharmacovigilance Systems; WHO: Geneva, Switzerland, 2004. 
36. Agyei-Baffour, P.; Kudolo, A.; Quansah, D.Y.; Boateng, D. Integrating herbal medicine into mainstream healthcare in Ghana: Clients' acceptability, perceptions and disclosure of use. BMC Complement. Altern. Med. 2017, 17, 513. [CrossRef] [PubMed]

37. Zhang, J.; Onakpoya, I.J.; Posadzki, P.; Eddouks, M. The safety of herbal medicine: From prejudice to evidence. Evid. Based Complement. Alternat. Med. 2015, 2015, 3. [CrossRef] [PubMed] 